\title{
Reforming public hospital financing in China: progress and challenges
}

\author{
Jin Xu and colleagues describe the effects of the financing reforms of public hospitals and \\ suggests steps to further progress towards equitable, efficient, and good quality care.
}

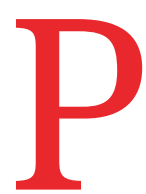

ublic hospitals provide most healthcare services in China. They employ $64 \%$ of licensed doctors, deal with $82 \%$ of inpatient admissions and $40 \%$ of ambulatory visits, and account for about half of China's total health expenditure. ${ }^{1}$ However, before 2009 public hospitals were faced with a perverse incentive structure that encouraged inefficient use of medical resources..$^{2-4}$

\section{A distorted funding system}

Public hospitals in China historically received funding mainly through service charges, drug sales, and government budget allocation (fig 1). In addition, the government also set the prices for pharmaceuticals and medical services provided in public hospitals. Service charges were low for most basic medical services (such as surgery, diagnosis, therapy, and nursing) but highly profitable for services involving advanced technologies such as computed tomography and magnetic resonance imaging. ${ }^{5}$ Hospitals also received cross subsidy (that is, non-direct subsidy for medical ser-

\section{KEY MESSAGES}

- Perverse financial incentives for public hospitals contributed to the inefficient use of medical resources in China before 2009

- Financing reform focused on removing drug mark-ups, increased budget allocation, adjusting fee schedules, and reforming payment methods

- The reform has substantially reduced hospitals' reliance on profit from pharmaceutical sales, while progress on the other measures is insufficient

- The varied quality of care, increasing hospital dominance, and growing costs to patients requires further reform

- We recommend consolidating the leadership in financing reform, implementing value based strategic purchasing, and allowing public hospitals greater management autonomy vices using profit allowed for other chargeable items) from a proportional mark-up (roughly 15\%) on drugs they dispensed. ${ }^{6}$ Service charges were collected from either social health insurance funds or individual patients on a fee-for-service basis. In other words, hospitals were rewarded for each additional service item provided.

As the government had neglected its fiscal responsibility to public hospitals since the 1980s, public hospitals became responsible for their own balance sheets. ${ }^{7}$ They relied increasingly on profits from excessive prescription of expensive medicines and uses of advanced technologies, contributing to escalating medical spending and financial burden on patients. By the early 2000s, the pharmaceutical sales revenue accounted for more than $40 \%$ of total revenue of public hospitals. ${ }^{1}$ Along with expanding coverage of social health insurance, the total revenue of public hospitals more than tripled from 2002 to 2008 . $^{1}$

To reorient the management and services of public hospitals towards public interests and enhance service efficiency and quality, the Chinese government listed public hospitals as one of five key areas in its health system reforms. ${ }^{8}$ Since 2009 the government has introduced policies to increase hospital budget allocation, adjust pricing of pharmaceuticals and medical services, reform payment methods, reinforce planning and governance, re-establish a referral system, and increase the role of the private sector. ${ }^{9-13}$ The government saw public hospital financing reform as an important lever to modify hospital service provision and guide distribution of medical resources. ${ }^{14}$

Our analysis focuses on what has been proposed and achieved in reforming public hospital financing in the past decade. We also discuss remaining challenges and propose recommendations for further reform.

\section{Financing reform}

The financing reform focused on four interrelated areas: removing the drug mark-up, increased budget allocation, adjustments of fee schedules, and reforming payment methods. Various explorative pilots took place in selected areas before the reform rolled out (box 1).

The Chinese government reduced drug mark-up (except for herbal traditional Chinese medicines) in public hospitals incrementally until it was removed entirely in 2018 (box 1). It also set a target of reducing the proportion of pharmaceuticals in total hospital revenue to $30 \% .^{13}$ Increased prices for medical services would cover $40-90 \%$ of the revenue that hospitals lost from removing the mark-up, depending on provincial contexts; $10-50 \%$ would be covered by additional government subsidies, with the remainder borne by hospitals through efficiency gains from improved management (see web appendix).

For government subsidies, the actual arrangement depended on the municipal or

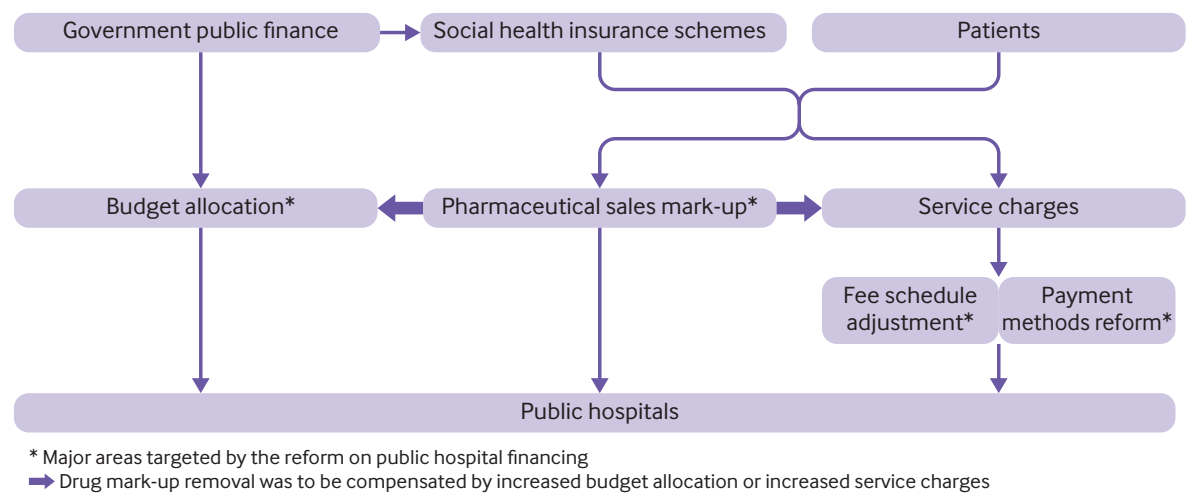

Fig 1 | Revenue sources of public hospitals and reform objectives from 2009 to 2018 
2009: Central Committee of Communist Party of China and State Council (Zhongfa [2009] No 6)

Set up pharmaceutical services fee; adjust fee schedule; increase government budget allocation

2009: State Council (Guofa [2009] No 12)

To specify short term (2009-11) reform priorities:

To incrementally remove drug mark-up from hospital financing; to set up pharmaceutical services fees and include them in social health insurance benefits; to increase service prices; to provide budget allocation to subsidise public hospitals for infrastructure, major equipment, disciplinary development, retirees' pension, and a range of public health activities

2011: National Development and Reform Commission, Ministry of Health (Fagaijiage [2011] No 674)

To implement disease based payment pilots for common diseases with standardised clinical pathways and clear treatment benefits

2012: State Council (Guofa [2012] No 11)

To launch disease based payment combined with clinical pathway

2012: Ministry of Health (Weinongweifa 2012 No 28)

To shift new rural cooperative medical schemes from fee-for-service towards mixed payment

2012: Ministries of Human Resources and Social Security, Finance, and Health (Renshebufa [2012] No 70)

To launch global budget control for social health insurance schemes, with sharing of surplus or deficit proposed

To explore capitation payment, disease based payment, etc

2015: State Council General Office (Guobanfa [2015] No 33)

To roll out comprehensive public hospital reform in about 2000 counties, including payment system, reducing use of fee-for-service

2015: State Council General Office (Guobanfa [2015] No 38)

To roll out comprehensive public hospital reform in about 200 pilots cities, including payment system, reducing use of fee-for-service

2015: State Council General Office (Guobanfa [2015] No 70)

To implement tiered healthcare system and use payment structure to incentivise secondary and tertiary hospitals to refer patients with defined diagnoses and stable conditions to primary care facilities

2017: State Council General Office (Guobanfa [2017] No 55)

To implement mixed payment:

- Inpatient care: using mainly disease and diagnostic-related-group (DRG) based payment, while long term and chronic hospital admissions can be paid by the day

- Ambulatory care: exploring capitation based payment for both hospital and primary care services held by primary care facilities

- Fee for services for cases that are not suitable for bundled payment

- Adding a points system to the current global budget control and starting to change the unit of global budget control from facilities to all facilities within an area

2017: Ministry of Finance, Human Resource and Social Security, National Commissions of Development and Reform, and Health and Family Planning, State Administration of Traditional Chinese Medicine and State Commission Office of Public Sectors Reform (Guoweitigaifa [2017] No 22)

To remove drug mark-up (except for traditional Chinese herbal medicines) in all public hospitals

2018: Central Committee of Communist Party of China

To establish National Healthcare Security Administration (NHSA), incorporating the responsibility for urban basic medical insurance schemes previously under the Ministry of Human Resources and Social Security, the responsibility for the new cooperative medical schemes previously under National Health and Family Planning Commission, the responsibility for managing prices for pharmaceuticals and medical services of the National Development and Reform Commission, and the responsibility for medical assistance of the Ministry of Civil Affairs into this new administration

2018: NHSA (Yibaobanfa [2018] No 23)

To launch national pilots of DRG based payment

county governments that were responsible for the hospitals. Provincial governments, which set prices for medical services, introduced a "general consultation fee" for each patient visit or admission to substitute drug mark-up (see web appendix). In addition, some provinces increased the prices of professional services. ${ }^{15}$

Although fee-for-service remained the predominant payment method, the country has been moving towards a mixed payment scheme. ${ }^{16}$ A global budget control was launched nationwide in 2012, ${ }^{13}{ }^{17}$ setting an annual reimbursement cap for each health facility. Generally, the caps were to some extent arbitrary and based on historical revenues. ${ }^{18}$

About two thirds of hospitals implemented disease-based payment ${ }^{19}$ for conditions with well-defined admission criteria and treatment procedures. Under disease based payment, hospitals received a fixed reimbursement for treating patients with certain diseases and were also rewarded if they had a high proportion of cases registered and compliant with standard clinical pathways. Some local governments also piloted payment based on diagnosis related groups (DRGs), which distinguishes diagnoses further by their clinical procedures, costs, complexities, individual patient factors, etc. ${ }^{20}$ Others piloted a prospective global budget for integrated delivery systems incorporating hospitals and primary care facilities (dubbed "medical alliance"), which were paid a fixed annual amount by social health insurance. Hence, the hospitals were rewarded for cutting costs and investing in prevention while maintaining health status of the population in collaboration with primary care facilities. 
The financing reform was implemented along with broader reform. The government emphasised the importance of systemic and coordinated reform in pharmaceutical manufacture and distribution, social health insurance, and hospital organisation. One result was the establishment of the National Healthcare Security Administration (NHSA) in 2018. The NHSA not only assumed administrative responsibility for all social insurance schemes but also incorporated previously separated purchasing power, including price setting, procurement, and provider payments. ${ }^{21}$ From 2015, the reform was also linked with a systemic effort to develop a referral system with multiple tiers of services, including both hospitals and primary care facilities, as government recognised the need to move away from over-reliance of medical services on hospitals (box 1).

\section{Achievements}

Removal of the drug mark-up seems to have decreased pharmaceutical sales. By 2017, pharmaceuticals accounted for $31 \%$ of public hospitals' revenue, down from above $40 \%$ before 2009 , just as profit from pharmaceutical sales contributed an increasingly smaller proportion of hospitals' disposable revenue (net revenue after payment to pharmaceutical suppliers) (fig 2). A nationwide analysis showed a $6.5 \%$ decrease in drug expenditures per visit, and a 9.5\% decrease in drug expenditures per admission because of the mark-up removal. ${ }^{22}$ The budget allocated to public hospitals increased from $¥ 5$. $2 \mathrm{bn}$ to $¥ 23.5 \mathrm{bn}$, though its proportion of hospitals' disposable revenue (ie, earnings after paying pharmaceutical suppliers) was stable around $12.6 \%$ (fig 2). ${ }^{1}$ Adjustment of fee schedules seems to have compensated for the lost mark-up overall. Revenue from medical services in county hospitals increased by $8.2 \%$ after mark-up removal, with their total revenue unaffected..$^{22}$ The same study also found no observable effect on patient visits and admissions. In Beijing, the service fee adjustment encouraged a substantial number of patients to seek care at primary care facilities. ${ }^{15}$

Along with the payment reforms, annual growth rates of hospitals' disposable revenue went down from $19.9 \%$ between 2008 and 2012 to $11.7 \%$ between 2013 and 2017 (fig 3). A local DRGs based payment pilot reduced patient charges per admission without compromising the quality of care. ${ }^{24}$ The bundled payment pilot for medical alliance suggested early signs of improved coordination of care

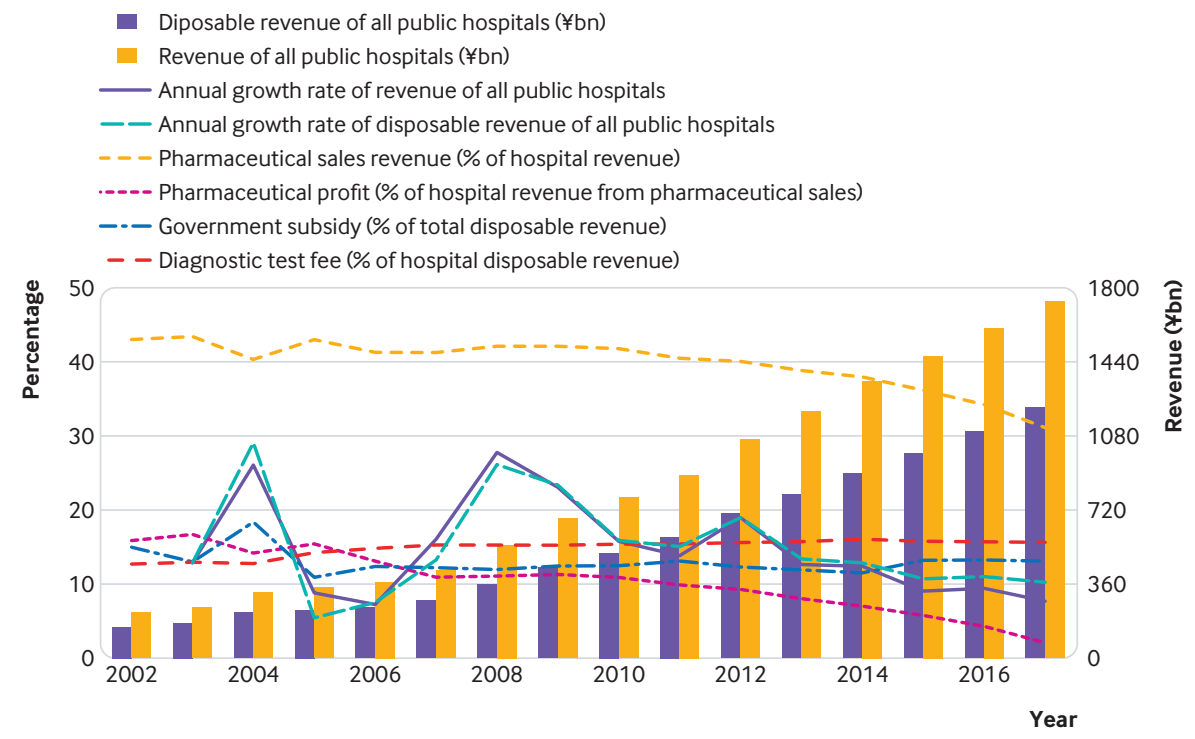

Fig 2 | Revenues of public hospitals and growth rates, 2002-17. ${ }^{1}$ Data for government owned hospitals under the health sector were used from 2002 to 2007, as data for all public hospitals (which includes those owned by state owned enterprises, etc) were not reported for these years. Pharmaceutical sales profit=hospital revenue from pharmaceutical sales (using total inpatient and outpatient charges on medicines)-pharmaceutical fees paid by hospitals to pharmaceutical suppliers. Revenue has been adjusted by dividing the original data (based on current prices) with the inflation rates calculated from consumer price index numbers since the base year (2002) according to the China Statistical Yearbook 2018. Total disposable revenue $=$ total revenue - pharmaceutical costs

for chronic diseases but short term costs increased. ${ }^{25}$

\section{Remaining challenges}

Despite the financing reform, quality and efficiency of hospital services are still suboptimal. Substantial variations still exist in the quality of hospital care in China. ${ }^{2627}$ Meanwhile, hospitals in China continue to expand rapidly. From 2008 to 2017, the number of visits to hospitals increased by $93.1 \%$ compared with an increase of $49.5 \%$ to primary care facilities. Hospital admissions rose by 2.4 times from 2008 to 2017 (10\% on average annually). Hospital revenue was 5.2 times that of all primary care facilities in 2017, up from four times in 2008. ${ }^{1}$ Indeed, the number of hospital beds in China is fast approaching the OECD average (fig 3).

Several problems also remain with the financing system. Budget allocation is tied to capital investment and local fiscal capacity rather than the needs of facilities or the population. ${ }^{28}$ In addition, the changes to payment scheme have not been entirely successful. Hospitals compensated for loss of income from the drug mark-up by using more diagnostic tests, ${ }^{22}$ potentially leading to overdiagnosis. Although budget controls have slowed down the growth of insurance spending, hospitals seem to have shifted cost to patients, resulting in rising out-of-pocket expenditure. ${ }^{29} \mathrm{~A}$ greater move to disease based payment could have improved the quality of care and contained costs by incentivising clinical standardisation, but the limited coverage of standard clinical pathways restricted the application and effectiveness of this system. ${ }^{3031}$ Other payment methods, such as those using diagnosis related groups, are yet to scale up.

Technical barriers have prevented use of value based purchasing. Fragmented information systems and lack of rigorous evaluation weakened the evidence base for financing hospitals. ${ }^{32}$ Bundling payment across facilities and the redistribution of surplus or deficit within network facilities require effective measurement of performance within facilities, which is also lacking.

In addition, the reforms are yet to address two fundamental challenges. One is the discordance among agencies that supervise hospitals and pay for their services (using either fiscal budget or insurance funds). A pilot of a comprehensive financing reform in Beijing showed the importance of leadership structure in facilitating the design and implementation. ${ }^{15}$ The other challenge is that hospital managers lack the autonomy to carry out internal changes (eg, hiring/firing and salary) and establish new professional norms. ${ }^{33}$ After all, all 


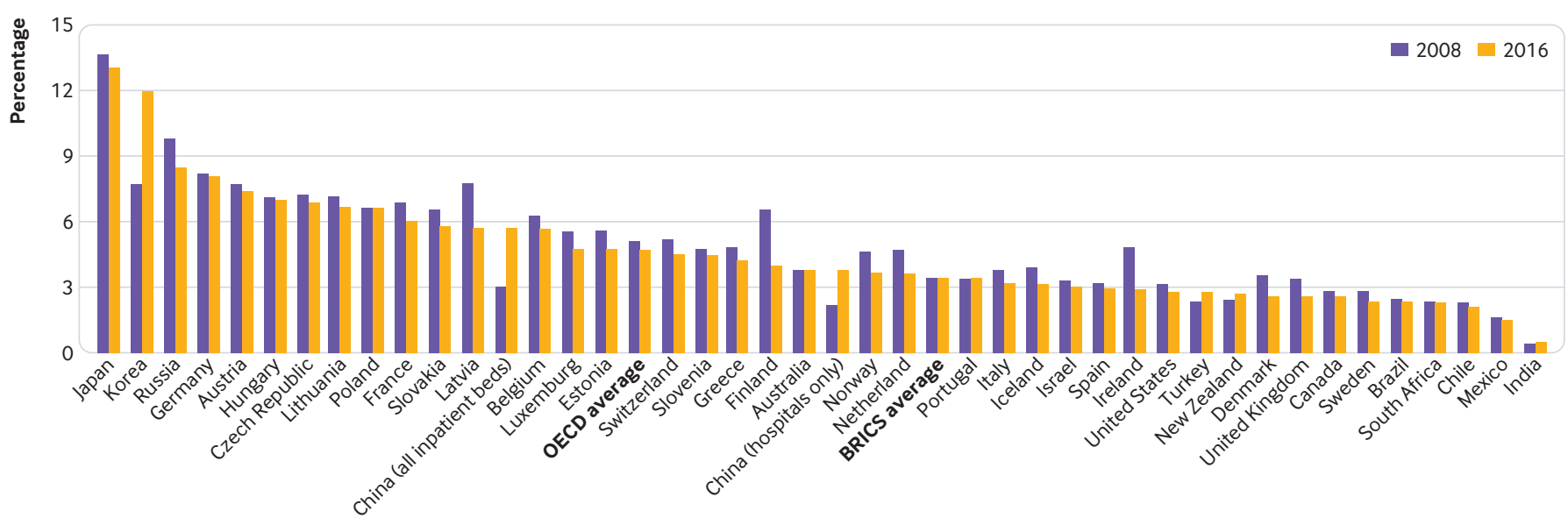

Fig $3 \mid$ Hospital beds per 1000 population in countries in the Organisation for Economic Cooperation and Development (OECD) plus BRICs (Brazil, Russia, India, China, South Africa), 2008-16 ${ }^{123}$

Note: For 2016, 2015 data are used for US, 2013 data for India, and 2011 data for South Africa. Note, in China, primary care facilities also have a lot of inpatient beds. Many of them have overlapping functions with hospital beds. This is included as "China (all inpatient beds)".

payment methods have flaws. ${ }^{34}$ Financing reform is better seen as the means to build institutions to help hospitals and doctors become agents for patients, rather than the end itself. ${ }^{35}$

\section{Recommendations}

Our analysis suggests several steps towards improved public hospital financing.

Consolidate leadership in financing reform of public hospitals-To address the current fragmented decision making and discordance in policies, further reform requires unified leadership of financing reform and joint purchasing of health services by the NHSA, the National Health Commission, and the Ministry of Finance, etc. and their corresponding agencies at local levels. These agencies should pool fund according to local context, set up joint supervision of hospitals' behavior and performance, and allow fund-receiving hospitals greater flexibility to decide how they use the resources.

Remove the technical barriers to strategic purchasing-National and regional governments need to build an integrated health information system that also allows monitoring of quality and outcome. This means standardisation of information system and sharing of data between health agencies and social health insurance agencies. Governments should finance independent research bodies and provide them with access to data to monitor and evaluate the effects of reform policies.

Adopt value-based strategic purchasing to align incentives with need, quality, and outcome-Payment for outpatient care should be changed from fee-for-service with a global budget cap to capitation with risk adjustment. The capitation budget should cover both primary care facilities and the outpatient department of hospitals. Payment for inpatient services should be based on diagnosis related groups. Provider payment should reward better quality and outcomes.

Adjust the mechanism of budget allocation-Budgets should be needs based and equalised across the country with an additional top-up related to quality and outcome, rather than tied to capital investment. The government should harmonise budget allocation for public hospitals with other channels of financing (particularly insurance) and with allocation to primary care facilities. Some hospitals may need additional short term subsidies to relieve the shock from losing the drug mark-up and facilitate their transit towards value-based service delivery.

Increase public hospital management autonomy-Public hospital directors should have the autonomy to handle human resources matters, including hiring and firing, salaries, etc. Wages for medical professionals should be sufficient and rely less on financial incentives, ${ }^{16}$ providing a nurturing environment for professionalism and evidence-based clinical practice. A greater portion of professional wages should be fixed, complemented by a performance-based top-up.

\section{Conclusion}

The removal of the long established drug mark-up policies constituted a milestone in China's public hospital reforms. Meanwhile, government budget allocation is still tied to capital investment and local fiscal capacity, the fee schedule is insufficiently adjusted, and progress on reforming payment methods has been patchy. As a result, hospitals have become increasingly dominant in China's health system and provided services with varied quality and at growing costs to patients. For the next stage of reform, we recommend consolidation of leadership in financing reform, removing the technical barriers towards strategic purchasing, implementing value-based purchasing, adjusting the mechanism of budget allocation, and greater autonomy in hospital management.

We thank Jianrong Qiao from the World Health Organization and Qingyue Meng and other colleagues at China Center for Health Development Studies, Peking University, for their helpful comments on drafts of this article, and Yang Bai for help in collecting provincial policy documents on compensating hospital revenue loss from mark-up removal.

Contributors and sources: JX specialises in health policy and systems research and focuses on primary care strengthening in the context of hospitals' dominance. WJ and KZ specialise in payment methods, social health insurance policies and health financing in general. SK and HF have studied and published widely on health financing and economics JX and HF conceived the framework of the paper. JX conducted literature review and data analysis, and wrote the first draft. All authors provided critical review on drafts of the paper.

Competing interests: We have read and understood BMJ policy on declaration of interests and have no relevant interests to declare.

Provenance and peer review: Commissioned; externally peer reviewed.

This article is part of a series proposed by Peking University China Center for Health Development Studies and commissioned by The BMJ. The BMJ retained full editorial control over external peer review, editing, and publication of these articles. Open access fees are funded by Peking University Health Science Center. 
Jin Xu, lecturer ${ }^{1}$

Weiyan Jian, associate professor ${ }^{2}$

Kun Zhu, associate senior research fellow ${ }^{3}$

Soonman Kwon, professor ${ }^{4}$

Hai Fang, professor

${ }^{1}$ China Center for Health Development Studies, Peking University, Beijing, China

${ }^{2}$ Peking University Health Science Centre, Beijing, China

${ }^{3}$ Chinese Academy of Fiscal Sciences, Beijing, China

${ }^{4}$ Seoul National University, Seoul, Korea

Correspondence to: IXu

xujin@hsc.pku.edu.cn

\section{(c) (1) 6} accordance with the Creative Commons Attribution Non Commercial (CC BY-NC 4.0) license, which permits others to distribute, remix, adapt, build upon this work non-commercially, and license their derivative works on different terms, provided the original work is properly cited and the use is non-commercial. See: http://creativecommons.org/ licenses/by-nc/4.0/.

\section{A) Check for updates}

1 National Health Commission. China national health statistical yearbook 2003-2018. Peking Union Medical College Press, 2003-2018.

2 Yip WC-M, Hsiao W, Meng Q, Chen W, Sun X. Realignment of incentives for health-care providers in China. Lancet 2010;375:1120-30. doi:10.1016/ S0140-6736(10)60063-3

3 Eggleston K, Ling L, Qingyue M, Lindelow M, Wagstaff A. Health service delivery in China: a literature review. Health Econ 2008;17:149-65. doi:10.1002/ hec 1306

4 Barber SL, Borowitz M, Bekedam H, Ma J. The hospital of the future in China: China's reform of public hospitals and trends from industrialized countries. Health Policy Plan 2014;29:367-78. doi:10.1093/ heapol/czt023

5 Liu X, Liu Y, Chen N. The Chinese experience of hospital price regulation. Health Policy Plan 2000;15:157-63. doi:10.1093/heapol/15.2.157

6 Zhang M, Bian Y. History of the policy of drug markup policy in hospitals in China and its Influences. Chinese Health Service Management 2007;7:465-6.

7 Duckett J. The Chinese state's retreat from health: Policy and the politics of retrenchment. Routledge, 2012.

8 Meng Q, Mills A, Wang L, Han Q. What can we learn from China's health system reform? BM 2019;365:I2349. doi:10.1136/bmj.l2349
9 Central Committee of Communist Party of China and State Council. Opinions on deepening health system reform. 2009. http://www.gov.cn/gongbao/ content/2009/content_1284372.htm.

10 State Council [The State Council's circular regarding the implementation plan for key points of health system reform in the near future (2009-2011)] [In Chinese]. G. No 12. 2009. http://www.gov.cn/ zwgk/2009-04/07/content_1279256.htm.

11 State Council. Implementation opinions of the State Council on comprehensively promoting the comprehensive reform of all public hospitals at the county level [In Chinese]. G. No 33. 2015. http:// www.gov.cn/zhengce/content/2015-05/08/ content $9710 . \mathrm{htm}$

12 State Council. Guiding opinions of the general office of the state council on urban public hospital comprehensive reform pilot [In Chinese]. G No 38. 2015.http://www.gov.cn/zhengce/ content/2015-05/17/content_9776.htm

13 State Council General Office. Guiding opinions on further deepening reform of basic medical insurance payment methods, G No 55. 2017. http://www.gov.cn/zhengce/content/2017-06/28/ content 5206315.htm

14 Meng Q., Review of health care provider payment reforms in China. World Bank, 2005

15 Liu X, Xu J, Yuan B, et al. Containing medical expenditure: lessons from reform of Beijing's public hospitals. BMJ 2019;365:12369. doi:10.1136/bmj. 12369

16 Shi R, Wei R, Zhang G. International experience on hospital salary system and implications for China[in Chinese]. HumanResources 2016;20:37-9.

17 Ministry of Human Resources and Social Security, Ministry of Finance, Ministry of Health. Opinions on implementing global budget control in provider payment by basic medical insurance funds. R No 70. 2012.http://www.mof.gov.cn/zhengwuxinxi/ zhengcefabu/201212/t20121205_709672.htm

18 Wang Z. Global budget control of social health insurance: questions and considerations[in Chinese]. Chinese Social Security 2017:4:80-1.

19 Beijing Youth Daily. China to specify more than 100 Items of disease-based payment [in Chinese]. Beijing Youth Daily 2017.

20 Yu B. Case-based payment and approaches to carry out payment method reform for medical services - on the basis of distinguishing DRGs, casebased payment, points-based system and clinical pathways[in Chinese]. Health Econ Rev 2018;9:16-8.

21 Xinhua. China establishes state medical insurance administration. Global Times 20181 Jun. http:// www.globaltimes.cn/content/1105123.shtml.

22 Fu H, Li L, Yip W. Intended and unintended impacts of price changes for drugs and medical services: Evidence from China. Soc Sci Med 2018;211:11422. doi:10.1016/j.socscimed.2018.06.007

23 OECD Statistics 2018. http://www.oecd.org/els/ health-systems/health-data.htm
24 Jian W, Lu M, Chan KY, et al. Payment reform pilo in Beijing hospitals reduced expenditures and out-of-pocket payments per admission. Health Aff (Millwood) 2015;34:1745-52. doi:10.1377/ hlthaff.2015.0074

25 Wang X, Sun X, Birch S, et al. People-centred integrated care in urban China. Bull World Health Organ 2018;96:843-52. doi:10.2471/ BLT.18.214908

26 Xu Y, Liu Y, Shu T, Yang W, Liang M. Variations in the quality of care at large public hospitals in Beijing, China: a condition-based outcome approach. PLoS One 2015;10:e0138948. doi:10.1371/journal. pone. 0138948

27 Zhou Y, Yao X, Liu G, Jian W, Yip W. Level and variation on quality of care in China: a cross-sectional study for the acute myocardial infarction patients in tertiary hospitals in Beijing. BMC Health Serv Res 2019:19:43 doi:10.1186/s12913-019-3872-0

28 Chen Q, Yin A, Qin X. Review on reform of converting compensation mechanism by abolishing the policy of compensating hospitals using revenue from pharmaceutical sales [in Chinese]. Chinese Heath Service Management 2012;10:726-8.

29 Fang $\mathrm{H}$, et al. Enhancing financial protection under China's social health insurance to achieve universal health coverage. BMJ 2019;365:12378. doi:10.1136/bmj.l2378

30 Xue D. The development of specific disease payment and key issues regarding its managemen [in Chinese]. Chinese Health Resources 2018;21: 27-31.

31 Zhu K. Current status and recommendations for county-level public hospitals to pay for diseasesbased on the practice of the project provinces[in Chinese]. Health Econ Rev 2019;36:5-8.

32 Liu X., Hua Y., Xue. C., Analysis of the development course of hospital informationization in China [in Chinese]. Chinese Journal of Health Informatics and Management 2016;13:142-52.

33 Allen P, Cao Q, Wang H. Public hospital autonomy in China in an international context Int I Health Plann Manage 2014;29:141-59. doi:10.1002/ hpm. 2200

34 Lewis M, Pettersson G. Governance in health care delivery-raising performance. Policy research working paper. Development Economics Department, Human Development Department, World Bank, 2009.

35 Soucat A, et al. Pay-for-performance debate: not seeing the forest for the trees. Health Systems Reform 2017;3:74-9.

Web appendix: Table of provincial policies for compensating loss of revenue from removal of drug mark-up

Cite this as: $B M / 2019 ; 365: 14015$ http://dx.doi.org/10.1136/bmj.l4015 